\title{
PELATIHAN PERMAINAN MATEMATIKA DAN PENERAPANNYA DALAM PEMBELAJARAN BAGI GURU-GURU MI NW NURUL HARAMAIN NARMADA KABUPATEN LOMBOK BARAT
}

\author{
Arjudin", Sudi Prayitno, Baidowi, Harry Soeprianto \\ Mathematics Educations Study Program, Faculty of Training Teacher and Educations, \\ Mataram University, Indonesia
}

Kata Kunci:
pelatihan,
permainan
matematika,
penerapan,
pembelajaran

\begin{abstract}
Abstrak: Kegiatan pengabdian kepada masyarakat ini dilatarbelakangi permasalahan kurangnya minat belajar matematika di MI (Madrasah Ibtidaiyah) NW Nurul Haramain Narmada sebagai sekolah mitra. Permainan matematika merupakan solusi yang dapat mengatasi kurangnya minat belajar matematika sehingga meningkatkan kualitas baik proses maupun hasil pembelajaran di Sekolah Dasar/Madrasah Ibtidaiyah. Pengabdian kepada masyarakat ini bertujuan untuk meningkatkan pengetahuan dan keterampilan guru-guru Madrasah Ibtidaiyah tentang permainan matematika dan penerapannya dalam pembelajaran di kelas. Kegiatan pengabdian kepada masyarakat ini telah dilaksanakan dilaksanakan pada tahun ajaran 2019/2020. Pengabdian kepada masyarakat dilaksanakan dalam bentuk kegiatan yang terdiri dari: (1) Diskusi terfokus FGD (Focus Group Discussion) peningkatan wawasan permainan matematika, (2) Workshop penyusunan rencana pembelajaran dengan metode permainan, dan (3) Penerapan permainan matematika dalam praktek pembelajaran dalam lingkup terbatas. Kegiatan pengabdian pada masyarakat ini dirasakan sangat bermanfaat bagi peserta dalam hal: menambah wawasan guru-guru MI NW Nurul Haramain Narmada tentang permainan matematika, dan meningkatnya profesionalisme guru-guru MI NW Nurul Haramain Narmada dalam kaitannya dengan pelaksanaan pembelajaran yang berbasis permainan matematika, serta memperkaya pengetahuan guru-guru MI NW Nurul Haramain Narmada dalam meningkatkan minat belajar siswa-siswanya terhadap pelajaran matematika. Manfaat yang diperoleh para peserta hendaknya dapat diterapkan dan disebarluaskan pada teman-teman sejawatnya terutama di kelompok kerja madrasah (KKM) dalam menunjang peningkatan pengetahuan tentang permainan matematika dan keterampilan menerapkan permainan matematika tersebut dalam pembelajaran di kelas.
\end{abstract}

\section{Korspodensiemail: arjudin@unram.ac.id}

\section{PENDAHULUAN}

Bidang pendidikan merupakan komponen yang sangat penting sebagai salah satu penentu suksesnya pembangunan nasional. Mengingat pentingnya pendidikan, pemerintah senantiasa memberikan perhatian terhadap sekolah baik berupa bantuan untuk pembangunan fisik maupun peningkatan mutu sekolah. Agar bantuan tersebut mencapai sasaran yang diinginkan, sekolah harus dapat mengelola bantuan-bantuan tersebut seefektif mungkin untuk kemajuan sekolah yang bersangkutan.

Salah satu indikator peningkatan mutu pada suatu jenjang pendidikan adalah meningkatnya kemampuan siswa baik menyangkut substansi pelajaran maupun berkembangnya kreativitas, daya nalar, sikap, dan budi pekerti para siswa. Untuk mencapai hal ini, sekolah harus senantiasa meningkatkan mutu pembelajaran melalui inovasi-inovasi pembelajaran yang dapat meningkatkan minat, kemampuan dan kreativitas siswa. 
Matematika merupakan salah satu dari tiga mata pelajaran dalam Ujian Nasional (UN) Sekolah Dasar/Madrasah Ibtidaiyah, di mana mata pelajaran yang lain adalah Bahasa Indonesia dan IPA. Hal ini menunjukkan pentingnya pelajaran Matematika sebagai pondasi keilmuan untuk jenjang yang lebih tinggi. Matematika merupakan ilmu yang terstruktur, dimana suatu konsep akan terkait dengan konsep yang lain dengan urutan yang logis. Dengan demikian Matematika merupakan landasan keilmuan (basic science) sebagai pondasi pengembangan ilmu pengetahuan dan teknologi.

Pada hakekatnya Matematika berkenaan dengan ide-ide, struktur-struktur, dan hubungan-hubungan yang bersifat teratur menurut urutan yang logis (Hudoyo, 1979: 90). Sedangkan menurut Bell (1981: 108) bahwa konsep Matematika adalah ide abstrak yang memungkinkan seseorang untuk mengklasifikasikan obyek-obyek atau kejadian, memilih atau menentukan obyek atau kejadian apakah merupakan contoh atau bukan contoh dari ide abstrak tersebut. Dengan demikian untuk mengetahui siswa sudah memahami suatu konsep/definisi atau belum, siswa harus dapat menunjukkan mana contoh dan mana bukan contoh.

Struktur Matematika dimulai dari dasar-dasar yang disepakati bersama yang berupa istilah/konsep pangkal. Selanjutnya terdapat hubungan antara konsep-konsep pangkal tersebut yang disepakati kebenarannya, yang disebut aksioma atau postulat (Hudoyo \& Sutawidjaja, 1997: 105). Berdasarkan aksioma-aksioma ini dikembangkan pernyataanpernyataan baru yang berupa definisi, teorema atau dalil, lemma, dan sebagainya. Setiap pernyataan-pernyataan baru harus digali atau berdasarkan pernyataan sebelumnya. Sehingga dalam pembelajarannya, siswa harus memahami suatu materi dengan baik sebelum dapat melanjutkan materi berikutnya. Dengan demikian kemampuan atau kompetensi pada suatu jenjang pendidikan sangat diperlukan untuk menempuh jenjang berikutnya.

Agar dapat berhasil mencapai tujuan pembelajaran yang diinginkan, guru harus mempersiapkan dan melaksanakan pembelajaran dengan mengacu pada teori belajar dan perkembangan-perkembangan pembelajaran. Jerome S. Bruner, seorang ahli psikologi kognitif, mengemukakan teori belajarnya yang lebih peduli terhadap proses belajar daripada hasil belajar. Sedangkan mengenai proses belajar, ahli teori belajar Zoltan P. Dienes meyakini bahwa dengan berbagai sajian tentang suatu konsep Matematika, anak-anak akan dapat memahami secara penuh konsep tersebut jika dibandingkan dengan hanya menggunakan satu macam sajian saja. (Karim, dkk, 1997 : 19).

Permasalahan yang terjadi di kebanyakan sekolah, termasuk MI (Madrasah Ibtidaiyah) NW Nurul Haramain Narmada Lombok Barat, bahwa Matematika dipandang oleh sebagaian besar siswa sebagai pelajaran yang sulit dan tidak menarik. Persepsi yang tidak sepenuhnya benar ini harus diubah agar siswa tertarik untuk belajar Matematika. Hirdjan (1994:1) menyatakan bahwa salah satu cara untuk mengurangi bahkan mungkin menghilangkan anggapan sebagian besar siswa bahwa matematika merupakan mata pelajaran yang sukar dan kurang menarik, yaitu dengan dimungkinkan siswa melakukan hal-hal yang unik dan menarik serta melibatkan siswa dalam suatu permainan matematika.

Menurut teori perkembangan kognitif dari Piaget, anak usia SD berada pada tingkat berfikir kongkret. Sesuai dengan usianya, maka kegiatan pembelajaran dapat diwujudkan dalam bentuk kegiatan fisik, yaitu permainan atau bermain. Bermain ialah setiap kegiatan 
yang dilaksanakan sehingga menimbulkan kesenangan tanpa mempertimbangkan hasil akhir (Mahmudi, dkk., 2012: 135). Sedangkan menurut Semiawan (2008: 20), bermain adalah suatu kegiatan yang serius, tetapi mengasyikkan.

Dalam pembelajaran Matematika, guru harus senantiasa mengembangkan inovasi pembelajaran yang dapat meningkatkan minat siswa terhadap pelajaran Matematika. Salah satu inovasi pembelajaran yang dapat meningkatkan minat siswa adalah pembelajaran berbasis permainan, Langkah-langkah yang harus dilakukan untuk pembelajaran berbasis permainan antara lain:

1. Guru membagi siswa menjadi beberapa kelompok. Kelompok siswa yang dibentuk merupakan pencampuran yang ditinjau dari latar belakang sosial, jenis kelamin, dan kemampuan belajar mereka.

2. Guru menjelaskan petunjuk serta prosedur pelaksanaan permainan tersebut.

3. Berikan waktu siswa untuk melakukan permainan itu dalam kelompoknya sambil mereka belajar sendiri menemukan konsep-konsep matematika yang termuat dalam satu permainan yang mereka mainkan.

4. Guru berperan penting dalam mengarahkan interaksi sosial siswa untuk mencapai tujuan dari pembelajaran.

5. Guru membimbing siswa agar bisa mengemukakan ide atau gagasan mereka tentang konsep yang telah mereka dapatkan dari permainan tadi

6. Masing-masing kelompok dapat menyampaikan idenya kepada siswa yang lain dan siswa lain bisa menanggapinya atau manyanggah pendapat temannya.

7. Setelah itu guru menyimpulkan dan menerangkan tentang konsep-konsep yang telah mereka dapatkan dari permainan-permainan itu (Nuraeni, 2013: 687).

Berdasarkan uraian di atas, perlu dilaksanakan pengabdian kepada masyarakat bagi guru-guru SD/MI, dengan judul "Pelatihan Permainan Matematika dan Penerapan dalam Pembelajaran Bagi Guru-guru MI NW Nurul Haramain Narmada Kabupaten Lombok Barat”.

Tujuan kegiatan pengabdian kepada masyarakat ini adalah: (1) Meningkatkan wawasan dan pemahaman guru-guru MI NW Nurul Haramain Narmada tentang permainan matematika, (2) Meningkatkan keterampilan guru-guru guru-guru MI NW Nurul Haramain Narmada dalam menerapkan permainan matematika pembelajaran. Adapun manfaat yang diharapkan dari kegiatan pengabdian kepada masyarakat ini, yaitu: (1) Para guru MI NW Nurul Haramain Narmada mempunyai wawasan tentang permainan matematika, (2) Kompetensi dan profesionalisme guru-guru MI NW Nurul Haramain Narmada dapat meningkat dalam kaitannya pelaksanaan pembelajaran yang berbasis permainan matematika, (3) Guru-guru MI NW Nurul Haramain Narmada dapat meningkatkan minat belajar siswasiswanya terhadap pelajaran matematika.

\section{METODE KEGIATAN}

Metode yang digunakan dalam melaksanakan kegiatan pengabdian kepada masyarakat ini terdiri dari tahap-tahap Diskusi Terfokus/FGD (Focus Group Discussion), Workshop, dan Praktek. Uraian tiap-tiap tahap sebagai berikut.

1. Diskusi Terfokus/FGD 
Diskusi terfokus (FGD) dilaksanakan untuk meningkatkan wawasan dan pengetahuan tentang permainan matematika, dimana pada tahap ini tim pengabdian kepada masyarakat menyajikan materi sebagai fokus bahan diskusi.

2. Workshop Rencana Pembelajaran

Dalam workshop ini peserta kegiatan pengabdian masyarakat, yaitu guru-guru MI NW

Nurul Haramain Narmada, menyusun rencana pelaksanaan pembelajaran (RPP) yang berbasis permainan matematika dengan didampingi tim pengabdian.

3. Praktek Pelaksanaan Pembelajaran

Tahap terakhir pelaksanaan pengabdian ini adalah penerapan permainan matematika dalam pembelajaran yang berupa praktek pelaksanaan pembelajaran pada lingkup yang terbatas melalui kegiatan peer teaching (pembelajaran sebaya).

\section{HASIL DAN PEMBAHASAN}

Kegiatan pengabdian kepada masyarakat ini dilaksanakan pada Hari Selasa, Tanggal 3 September 2019 bertempat di MI NW Nurul Haramain Narmada Kabupaten Lombok Barat yang diikuti oleh Pengawas, Kepala Sekolah, dan Guru/Ustadz/Pengasuh di MI NW Nurul Haramain Narmada dengan peserta sebanyak 20 orang. Adapun daftar nama peserta kegiatan pengabdian kepada masyarakat ini ditunjukkan pada Tabel 1 berikut.

Tabel 1. Daftar Peserta Kegiatan Pengabdian Kepada Masyarakat

\begin{tabular}{|l|l|l|}
\hline No. & Nama Peserta & Keterangan \\
\hline 1. & Sri Ramadana, S.H. & Kepala MI \\
2. & Iin Haryaningsih K. & Guru \\
3. & Vedra Octa Samira & Guru \\
4. & Masithoh, S.Pd. & Guru \\
5. & Mita Susilastika & Guru \\
6. & Harmayana & Guru \\
7. & Rayhanun HIdayati & Guru \\
8. & Baiq Ellin Puspita & Guru \\
9. & Siti Rohana & Guru \\
10. & Asrini Fitri & Guru \\
11. & Ayu Mistari & Guru \\
12. & Wandi Purnama & Guru \\
13. & Firdaus & Guru \\
14. & M. Muhibbin & Guru \\
15. & Muh. Hendrian Dahri & Guru \\
16. & Dedi Irawan & Guru \\
17. & Didi Firmansyah & Guru \\
18. & Nurjuniya NIngsih & Guru \\
19. & Rahmah Nurmahani & Guru \\
20. & Miftahussaadah & Guru \\
\hline
\end{tabular}


Adapun foto peserta pada waktu mengikut kegiatan pengabdian kepada masyarakat ini disajikan pada Gambar 1 berikut.

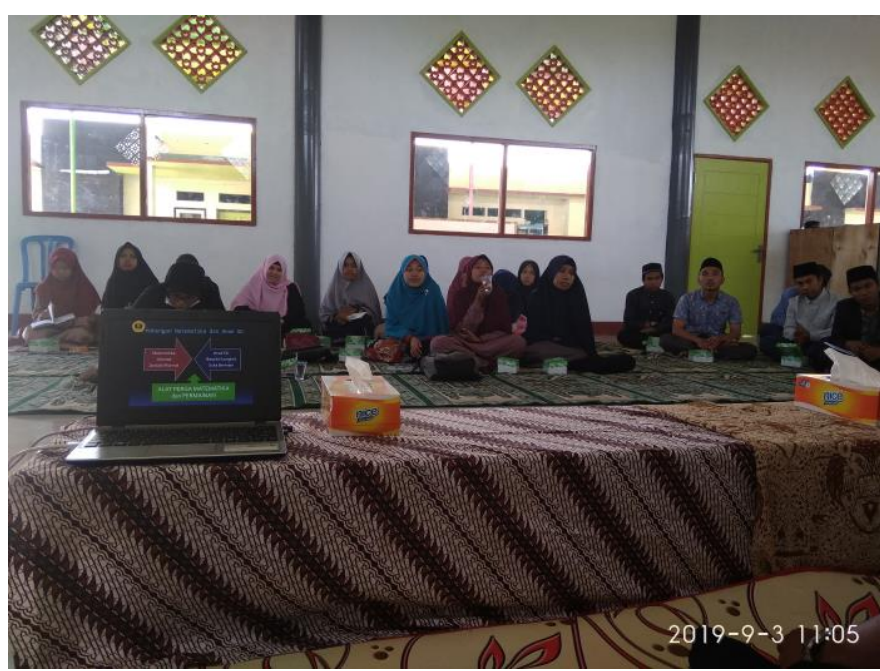

Gambar 1. Peserta Kegiatan Pengabdian Kepada Masyarakat

Kegiatan Diskusi Terfokus (FGD) diawali dengan penyajian materi untuk memfokuskan materi diskusi. Materi 1 tentang Teori tentang Metode Permainan dalam Pembelajaran Matematika, yang intinya bahwa anak usia SD/MI berada pada taraf berpikir konkrit dan masih dalam dunia suka bermain. Di pihak lain, bahwa pada hakekatnya matematika mencakup materi yang bersifat abstrak dan menuntut cara berpikir deduktif formal. Oleh karena itu diperlukan alat peraga matematika dan metode permainan dalam pembelajaran matematika. Metode permainan matematika bertujuan untuk menciptakan pembelajaran menyenangkan sehingga terjalin komunikasi yang baik antara guru dan siswa. Dibanding metode ekspositori, metode permainan matematika juga lebih banyak melibatkan indra tubuh dalam pembelajaran dari mendengar, melihat, berbicara, melakukan kegiatan. Semakin banyak indera yang dimanfaatkan oleh siswa, semakin baik retensi (daya ingat) siswa. Gambar 2 berikut memperlihatkan foto kegiatan penyajian materi teori tentang metode permainan matematika.

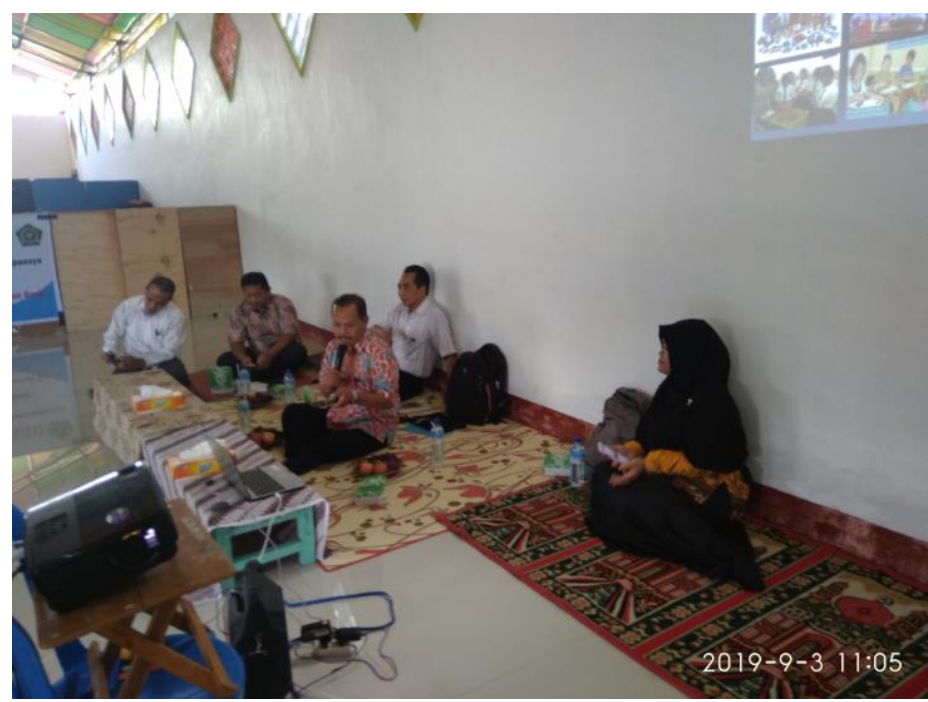

Gambar 2. Penyajian Materi Teori tentang Metode Permaina Matematika 
Penyajian materi ke-2 tentang Permainan Matematika Topik Teori Bilangan. Penyajian materi ini meliputi tiga permainan matematika, yaitu tebak angka, penjumlahan bersusun cepat, dan persegi ajaib. Pada permainan tebak angka, dilakukan sebagai berikut: (1) Siswa diminta menulis suatu bilangan (yang besar/lebih dari 100), (2) Jumlahkan angka-angka pada bilangan tersebut, (3) Sembunyikan salah satu angka pada bilangan tersebut, selain 0, (3) Kurangi bilangan yang diperoleh dengan jumlah angka tadi, (2) Sebutkan hasil yang diperoleh, dan (4) Penyaji permainan bisa tebak angka berapa yang disembunyikan. Permainan tebaak angka ini berkaitan dengan ciri-ciri bilangan habis dibagi 9. Permainan menjumlah bersusun dengan cepat juga menggunakan sifat dari kelipatan 9, dimana siswa dan guru menuliskan bilangan secara bergantian, misalnya sebanyak tiga kali, dan pada giliran terakhir guru menjumlahkan dengan cepat. Pada permainan persegi ajaib, untuk ukuran 3 x 3 peserta diminta mengisinya dengan angka 1 s/d 9 sehingga angka-angka pada setiap baris, kolom, dan diagonal berjumlah sama. Gambar 3 berikut memperlihatkan foto kegiatan penyajian materi permainan matematika topik teori bilangan.

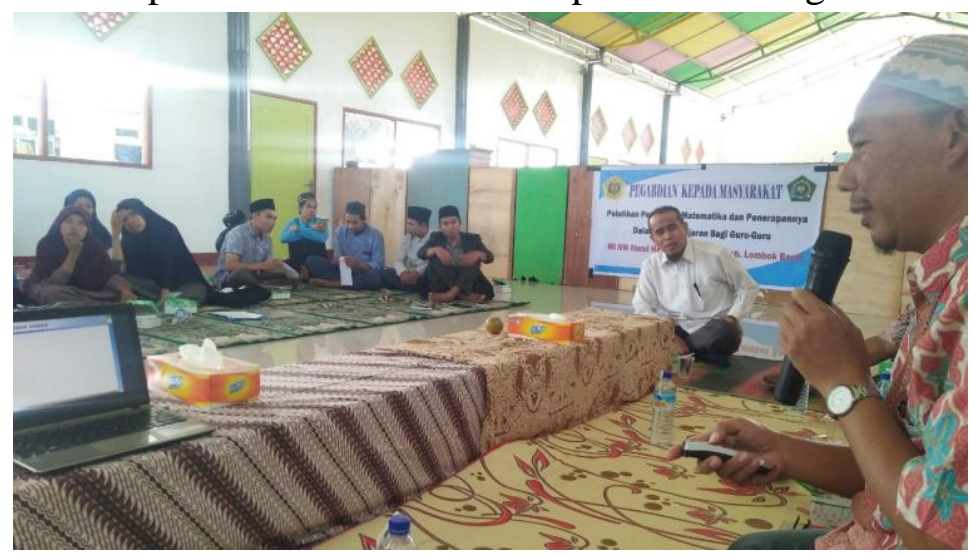

Gambar 3. Penyajian Materi Permainan Topik Teori Bilangan

Penyajian materi ke-3 tentang Permainan Matematika Aljabar. Penyajian materi ini meliputi permainan baris berbaris dan permainan ceker/manik-manik dalam operasi bilangan bulat. Pada permainan baris berbari, diperlukan sarana lantai bertegel atau halaman tanah yang diberi tanda seperti lantai bertegel disesuaikan dengan keadaan sekitar. Sedangkan aturan permainan baris-berbaris untuk penjumlahan bilangan bulat adalah sebagai berikut: (1) Sumbu garis bilangan positif menghadap ke kanan, negatif ke kiri, (2) Seorang peraga (demonstrator/pemain) awalnya berdiri pada angka nol dan menghadap ke kanan, (3) Bilangan positif A didefinisikan dengan bergerak maju A langkah, (4) Bilangan negatif B ( B ) didefinisikan dengan bergerak mundur B langkah, (5) Operasi penjumlahan diartikan tidak mengubah arah, (6) Operasi pengurangan diartikan balik kanan (membalikkan badan), (7) Hasil penjumlahan atau pengurangan ditunjukkan tempat terakhir berdiri. Sedangkan pada permainan ceker/manik-manik menggunakan sekumpulan benda identik yang dibedakan menjadi dua kelompok, misalnya berdasarkan warna. Salah satu warna disepakati sebagai tanda bilangan positif, dan warna yang lain sebagai bilangan negatif. Operasi penjumlahan dimaknai sebagai menambahkan ceker/manik-manik, sedangkan operasi dimaknai sebagai mengambil ceker/manik-manik. Hasil dari operasi ditunjukkan dengan banyaknya 
ceker/manik-manik yang tidak berpasangan. Gambar 4 berikut memperlihatkan foto kegiatan penyajian materi permainan matematika topik aljabar.

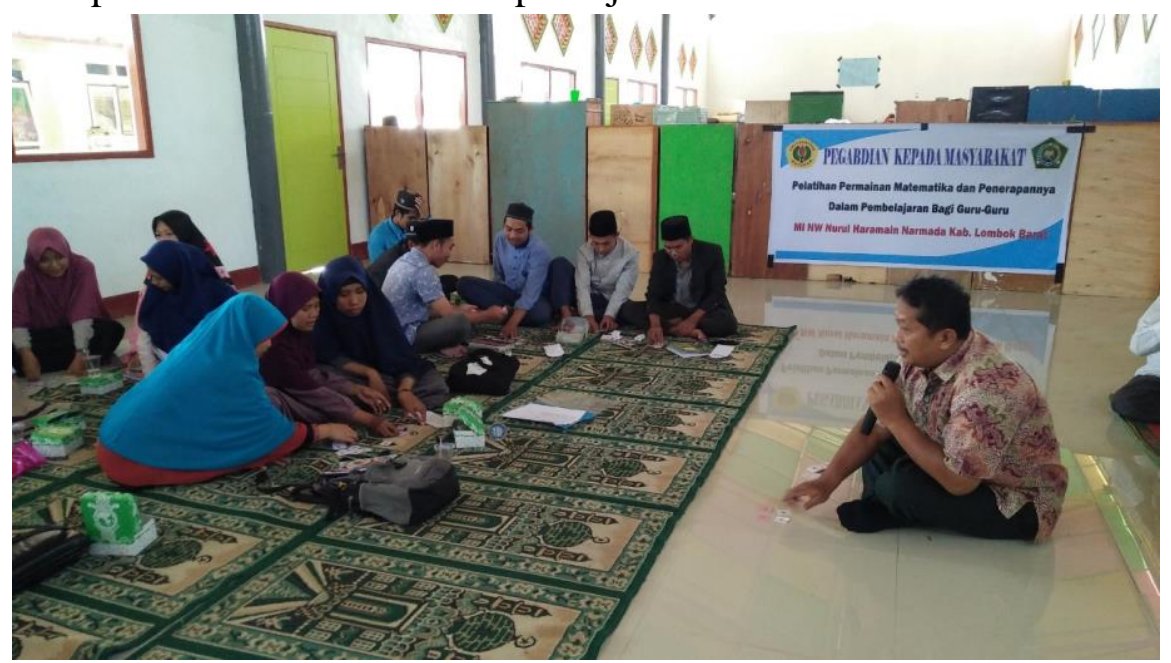

Gambar 4. Penyajian Materi Permainan Topik Aljabar

Kegiatan FGD dilanjutkan dengan diskusi dan tanya jawab. Peserta antusias memberikan tanggapan terkait tema permainan matematika. Gambar 5 memerlhatkan suasana tanya jawab dan diskusi tentang permainan matematika.

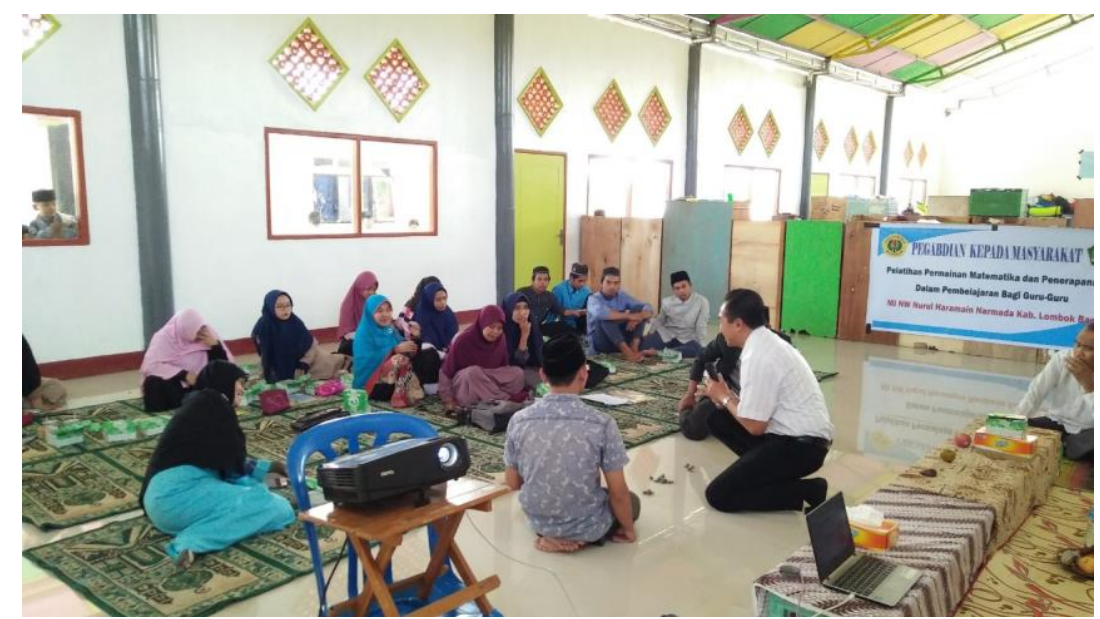

Gambar 5. Tanya jawab dan diskusi tentang permainan matematika

\section{KESIMPULAN DAN SARAN}

Berdasarkan hasil observasi selama kegiatan berlangsung dan hasil evaluasi setelah selesai kegiatan pengabdian kepada masyarakat ini, dapat disimpulkan bahwa kegiatan pengabdian pada masyarakat ini sangat bermanfaat bagi guru-guru MI NW Nurul Haramain Narmada Kabupaten Lombok Barat, yaitu dalam hal:

1. Menambah wawasan guru-guru MI NW Nurul Haramain Narmada Kabupaten Lombok Barat tentang permainan Matematika.

2. Meningkatkan pengetahuan guru-guru MI NW Nurul Haramain Narmada Kabupaten Lombok Barat dalam memotivasi siswa untuk tertarik pada pelajaran matematika. 
3. Meningkatnya ketrampilan guru-guru SDN 45 Mataram dalam membuat perencanaan pembelajaran Matematika yang menyenangkan melalui metode permainan matematika.

Adapun saran setelah dilaksanakan kegiatan pengabdian pada masyarakat ini, diharapkan kepada guru-guru MI NW Nurul Haramain Naramada agar pengetahuan dan ketrampilan yang diperoleh dalam pengabdian kepada masyarakat ini dapat diterapkan di kelas dan disebarluaskan pada teman-teman sejawatnya terutama di KKM (Kelompok Kerja Madrasah) tempat mereka berada.

\section{UCAPAN TERIMA KASIH}

Penulis mengucapkan terima kasih kepada Lembaga Penelitian dan Pengabdian kepada Masyarakat Universitas Mataram melalui Dana PNBP Tahun 2019 yang telah memberi dukungan financial terhadap pengabdian ini.

\section{DAFTAR PUSTAKA}

Bell, F.H. 1981. Teaching and Learning Mathematics (in Secondary School). Iowa : Wm. C. Brown Company.

Hirjan. 1994. Permainan Matematika, Jilid 1. Yogyakarta: FPMIPA IKIP Yogyakarta.

Hudoyo, H. 1979. Pengembangan Kurikulum Matematika dan Pelaksanaannya di Depan Kelas. Surabaya : Penerbit Usaha Nasional.

Hudoyo, H. \& Sutawidjaja, A. 1997. Matematika. Jakarta : Dirjen Dikti bagian Proyek Pengembangan Pendidikan Guru Sekolah Dasar.

Karim, Muchtar A., dkk. 1997. Pendidikan Matematika 1. Jakarta : Dirjen Dikti bagian Proyek Pengembangan Pendidikan Guru Sekolah Dasar.

Mahmudi, A., Andayani, S., Hernawati, K., Setyaningrum W, dan Yuli, F. 2012. Pelatihan Pembuatan Permainan Matematika dan Simulasinya dengan Perangkat Lunak Komputer untuk Menanamkan Sikap Positif terhadap Alam Sekitar Bagi Guru Sekolah Dasar Korban Bencana Merapi. Jurnal Inotek, Volume 16, Nomor 2.

Nuraeni, Z. 2013. Permainan Anak untuk Matematika. Prosiding Seminar Nasional Matematika dan Pendidikan Matematika, dengan tema "Penguatan Peran Matematika dan Pendidikan Matematika untuk Indonesia yang Lebih Baik" Jurusan Pendidikan Matematika FMIPA UNY, hlm. 683-690.

Semiawan, C. R. 2008. Belajar dan Pembelajaran Pra Sekolah dan Sekolah Dasar. Jakarta: PT. Indeks. 